\title{
Improvement of acromegaly control with multimodal therapy in Romania
}

\author{
Mihai C. Marinescu', Ionela Baciu1, 2, Nicoleta Baculescu, ${ }^{1,2}$, Cristina Am. Capatina ${ }^{1,2}$, Roxana Dusceac, ${ }^{1,2}$ \\ Simona A. Galoiu", 2, Dan A. Niculescu, ${ }^{1,2}$, Serban Radian ${ }^{1,2}$, Raluca A Trifanescu, ${ }^{1,2}$, Maria C. Baleanu', \\ Andra Caragheorgheopol', Catalina Poiana ${ }^{1,2}$
}

${ }^{1 " C . I . ~ P a r h o n " ~ I n s t i t u t e ~ o f ~ E n d o c r i n o l o g y, ~ B u c h a r e s t, ~ R o m a n i a ~}$

${ }^{2}$ Department of Endocrinology, "Carol Davila" University of Medicine and Pharmacy, Bucharest, Romania

\begin{abstract}
Introduction: In Romania, there is no acromegaly national register and there are no nationwide data available. However, some studies have reported the control rates in the country's main referral centres. Our aim was to assess the overall control rate in our tertiary referral centre. Also, we assessed the control rate in the last three years, and we compared the results with our previous reports.

Material and methods: We reviewed the charts of 186 patients with acromegaly assessed in our department between January $1^{\text {st }}, 2012$ and May 31st, 2019. We also compared the control rates for patients treated between April 1 ${ }^{\text {st }}, 2016$ and May $31^{\text {st }}, 2019$ with historical controls (assessed between January $1^{\text {st }}, 2012$ and March 31 $1^{\text {st }}, 2016$ ).

Results: Primary analysis: There were 19 untreated and 167 treated patients, mean age 52.46 years, surgery being the most commonly used treatment. The surgical cure rate was $14.8 \%$, and disease control with medical treatment was $35.3 \%$. Secondary analysis: In the first group there were 45 patients, surgery also being the most commonly used treatment. The surgical cure rate was $26.9 \%$, and disease control was $30.4 \%$. In the second group (historical controls) there were 42 patients, surgery being the most commonly used treatment. The surgical cure rate was $9.7 \%$, and disease control with medical treatment was $15.4 \%$. Random GH and IGF-1 after surgery were lower in the first group $(\mathrm{p}<0.05)$

Conclusions: Changes in the Romanian protocol and highly specialised pituitary centres has improved the cure rate and disease control in patients with acromegaly. (Endokrynol Pol 2020; 71 (3): 235-239)
\end{abstract}

Key words: acromegaly; control rate; treatment

\section{Introduction}

Acromegaly disease control has shown a significant improvement in the last years, particularly with multimodal therapy, including surgery, medical therapies, and radiotherapy [1]. Despite that, there is still a high variability of control rates in different centres [2-5] and countries [6-9]. Also, significant differences have been reported between sponsored clinical trials and real-life studies $[6,7,10-12]$. These large differences may be caused by different treatment protocols available in each country, which allow full reimbursement of treatment only in selected patients $[6,7,12,13]$.

In Romania, there is no acromegaly national register and there are no nationwide data available. However, some studies reported the control rates in the main referral centres of the country [14-16].
A study previously carried out in our centre showed disappointing results, with an overall control rate of $28 \%$ [16], significantly lower than in other European national registers $[6,9-12,17]$. These results are mostly due to poor surgical outcome (surgical cure rate 9.7\%) [16], also lower than in the available national registries $[6,9,12]$.

After the publication of previous studies, the Romanian treatment protocol for acromegaly was changed, so that the combination of somatostatin analogues (SSA) and growth hormone antagonist (Pegvisomant), and second-generation SSA (Pasireotide) became available and fully reimbursed by health insurance. Also, some new centres specialising in pituitary surgery became available.

Our aim was to assess the overall control rate in our tertiary referral centre. Also, we assessed the control rate in the last three years, with new available therapeutic options, and compared the results with our previous reports. 


\section{Material and methods}

\section{Subjects}

We reviewed the charts of all patients with confirmed acromegaly that were assessed at least once in our department between January $1^{\text {st }}, 2012$ and May 31 $1^{\text {st }}, 2019$. During this period, we assessed 186 patients with confirmed acromegaly. After exclusion of 19 patients who were not assessed after at least one treatment, we observed the surgical cure rate and overall disease control in the remaining 167 treated patients (primary analysis) (Tab. 1).

In the secondary analysis we evaluated only the patients diagnosed after January $1^{\text {st }}, 2012$ and compared the control rates for patients diagnosed and treated after the new reimbursement protocol (Group 1 - between April 1't, 2016 and May 31 ${ }^{\text {st }}$, 2019) with historical controls (Group 2 - patients diagnosed, treated, and assessed between January $1^{\text {st }}, 2012$ and March $31^{\text {st }}, 2016$ ). Group 1 consisted of 45 patients with confirmed acromegaly, for 35 of whom we had posttreatment data. Group 2 consisted of 57 patients with confirmed acromegaly, for 42 of whom we had post-treatment data (Tab. 1). Acromegaly diagnosis and control

Acromegaly diagnosis was made according to Endocrine Society guidelines (18) by elevated age-adjusted insulin-like growth factor-1 (IGF-1) and confirmed by lack of suppression of growth hormone $(\mathrm{GH})$ below $1 \mathrm{ng} / \mathrm{mL}$ following documented hyperglycaemia during an oral glucose load test. Remission of acromegaly after surgery was defined also according to Endocrine Society guidelines as random $\mathrm{GH}<1 \mathrm{ng} / \mathrm{mL}$ and normal age adjusted IGF-1. If the post-surgical GH was higher than $1 \mathrm{ng} / \mathrm{mL}$, oral glucose load test was performed, and remission was considered if GH was suppressed below $0.4 \mathrm{ng} /$ $\mathrm{mL}$ [18]. Control of acromegaly was defined according to Endocrine Society guidelines: a random serum $\mathrm{GH}<1 \mathrm{ng} / \mathrm{mL}$ and an agenormalised serum IGF-1 value. The GH and IGF-1 values used for calculation of the control rate were those at the last evaluation [18].

\section{GH and IGF-1 assays}

Starting in January 2012 the C.I. Parhon National Institute of Endocrinology used the same assays for serum growth hormone (GH) and IGF-1 measurement according to the Endocrine Society Guidelines for Acromegaly.

We measured serum GH using a chemiluminescence assay (Liaison, Sallugia, Italy). The assay is referenced to the WHO Second International Standard 98/574 for somatropin (22-kDa recombinant DNA-derived materials), with a functional sensitivity of $0.05 \mathrm{ng} /$ $\mathrm{mL}$ and an analytical sensitivity of $0.009 \mathrm{ng} / \mathrm{mL}$.

We measured serum IGF-1 using a Liaison IGF-1 chemiluminescence assay (DiaSorin, Sallugia, Italy). The assay is referenced to the 02/254 International Standard for Insulin-like Growth FactorI NIBSC, with functional sensitivity of $15 \mathrm{ng} / \mathrm{mL}$ and an analytical sensitivity of $3 \mathrm{ng} / \mathrm{mL}$.

\section{Statistics}

Data are presented as number (percentage) or as median $\left(25^{\text {th }}-75^{\text {th }}\right.$ percentile). We used the Mann-Whitney test to analyse differences between paired groups, and covariance analysis to assess differences between groups with covariates, for data with normal distribution.

\section{Results}

\section{Primary analysis}

Between January 1st, 2012 and May 31 ${ }^{\text {st }}, 2019$ we assessed 186 patients with newly or previous diagnosed acromegaly, 60 males and 126 females, with mean age of $55.48( \pm 12.9)$ years. There were 19 untreated and 167 treated patients. Of the 167 treated patients 148 $(88.6 \%)$ had surgery, $70(41.9 \%)$ had radiotherapy, and $109(65.2 \%)$ were receiving medical treatment at their

Table 1. Cure rate

\begin{tabular}{|c|c|c|c|}
\hline & All patients & $\begin{array}{c}\text { January } 1^{\text {st }}, 2012-M a r c h 31^{\text {st }} \\
2016\end{array}$ & $\begin{array}{c}\text { April 1st } 2016-M a y 31^{\text {st }}, \\
2019\end{array}$ \\
\hline Patients assessed, n & 186 & 57 & 45 \\
\hline Patients treated, n (\%) & $167(89.7 \%)$ & $42(73 \%)$ & $35(77 \%)$ \\
\hline Surgery, $\mathrm{n}$ ( $\%$ of treated) & $148(88.6 \%)$ & $41(97 \%)$ & $26(72.2 \%)$ \\
\hline Normal GH, $\mathrm{n}$ (\% of surgery) & $38(25.6 \%)$ & $10(24.4 \%)$ & $12(46.1 \%)$ \\
\hline Normal IGF-1, n (\% of surgery) & $27(18.2 \%)$ & $6(14.6 \%)$ & $7(26.9 \%)$ \\
\hline Cured, $\mathrm{n}$ (\% of surgery) & $22(14.8 \%)$ & $4(9.7 \%)$ & $7(26.9 \%)$ \\
\hline Medical treatment, $\mathrm{n}$ (\% of treated) & $109(65.2 \%)$ & $26(63.4 \%)$ & $22(61.1 \%)$ \\
\hline Controlled $\mathrm{GH}, \mathrm{n}$ (\% of medical treatment ${ }^{*}$ ) & $50(60.9 \%)$ of 82 & $11(42.3 \%)$ & $13(56.5 \%)$ \\
\hline Controlled IGF-1, n (\% of medical treatment) & $49(48.0 \%)$ & $5(19.2 \%)$ & $7(30.4 \%)$ \\
\hline Controlled IGF1 \& GH, n (\% of medical treatment ${ }^{*}$ ) & $29(35.3 \%)$ & $4(15.4 \%)$ & $7(30.4 \%)$ \\
\hline Radiotherapy, n (\% of treated) & $70(41.9 \%)$ & $8(19 \%)$ & $5(13.8 \%)$ \\
\hline \multicolumn{4}{|l|}{ Overall control rate } \\
\hline $\mathrm{GH}^{*}$ & $108(77.0 \%)$ & $20(47.6 \%)$ & $24(56.5 \%)$ \\
\hline IGF-1 & $88(52 \%)$ & $11(26.2 \%)$ & $14(38.8 \%)$ \\
\hline GH \& IGF-1* & $78(46.7 \%)$ & $8(19 \%)$ & $14(38.8 \%)$ \\
\hline
\end{tabular}

Data are presented as $\mathrm{n}(\%) ;{ }^{*} \mathrm{GH}$ or GH\&IGF-1 control rate refers only to patients not receiving growth hormone antagonist treatment. GH — growth hormone; IGF-1 — insulin-like growth factor 1 
last evaluation (37 Octreotide LAR, 19 Lanreotide LAR, 9 Pasireotide LAR, 7 Pegvisomant, 17 Cabergoline, 20 combination of SSA and Pegvisomant) (Tab. 1).

Of the 148 patients who underwent pituitary surgery, $38(25.6 \%)$ had normal GH, $27(18.2 \%)$ patients had a normal age- and sex-adjusted IGF-1, and $22(14.8 \%)$ had both normal IGF-1 and GH after surgery.

Of the 109 patients receiving medical therapy 49 $(48.0 \%)$ had a normal age-adjusted IGF-1. Of the 82 patients receiving medical therapy not containing pegvisomant $\mathrm{GH}$, control (by random $\mathrm{GH}<1 \mathrm{ng} / \mathrm{mL}$ ) was obtained in $50(60.9 \%)$ patients. Both GH and IGF-1 control were obtained in $29(35.3 \%)$ patients.

Of the 70 patients treated with radiotherapy, 20 $(28.5 \%)$ had normal GH and $12(17.1 \%)$ had normal IGF-1. All of the patients with normal IGF-1 also had normal GH (17.1\% cure rate).

Overall, $108(77 \%)$ patients monitored by random $\mathrm{GH}$ had normal $\mathrm{GH}$ at their last visit, $88(52 \%)$ had normal IGF-1, and 78 (46.7\%) had both normal GH and IGF-1 at their last visit.

\section{Secondary analysis}

In group 1 (diagnosed between April 1 ${ }^{\text {st }}, 2016$ and May $\left.31^{\text {st }}, 2019\right)$ there were 45 patients (13 males) with mean age of 51.32 years, of whom 36 were assessed after at least one treatment: $26(72.2 \%)$ patients treated by surgery, $22(61.1 \%)$ patients with medical treatment (SSA, cabergoline, or combination of SSA with pegvisomant), and five $(13.8 \%)$ patients treated with radiotherapy. Of the 26 patients treated by surgery, $12(46.1 \%)$ patients had normalised $\mathrm{GH}$, and seven $(26.9 \%)$ had normal IGF-1 after surgery. All seven (26.9\%) patients with normal IGF-1 had also random GH. Of the 23 patients receiving medical treatment, $13(56.5 \%)$ had normal GH and seven $(30.4 \%)$ had normal age-adjusted IGF-1. Also, all seven $(30.4 \%$ ) patients had both normal age-adjusted IGF-1 and GH. After at least one treatment (surgical or medical), in the second group $25(56.5 \%)$ had normal GH and 14 (38.8\%) had normal age-adjusted IGF-1. The overall disease control rate in the first group was $38.8 \%$ (14 patients had both normal GH and IGF-1).

In group 2 (diagnosed between January $1^{\text {st }}, 2012$ and March $31^{\text {st }}, 2016$ ) there were 42 patients (11 males), with mean age 52.46 years, assessed after at least one treatment: $41(97.6 \%)$ surgery, $26(61.9 \%)$ medical therapy, and eight $(19.0 \%)$ radiotherapy. Of the 41 surgically treated patients, $10(24.3 \%)$ had normalised $\mathrm{GH}$, six $(14.6 \%)$ had normal age- and sex-adjusted IGF-1, and four $(9.7 \%)$ had normalised GH and IGF-1. Of the 26 patients receiving medical treatment, $11(42.3 \%)$ had normal GH, five $(19.2 \%)$ had normal IGF-1, and four $(15.4 \%)$ had normal GH and IGF-1. After at least one treatment, in the second group, 20 patients $(47.6 \%)$

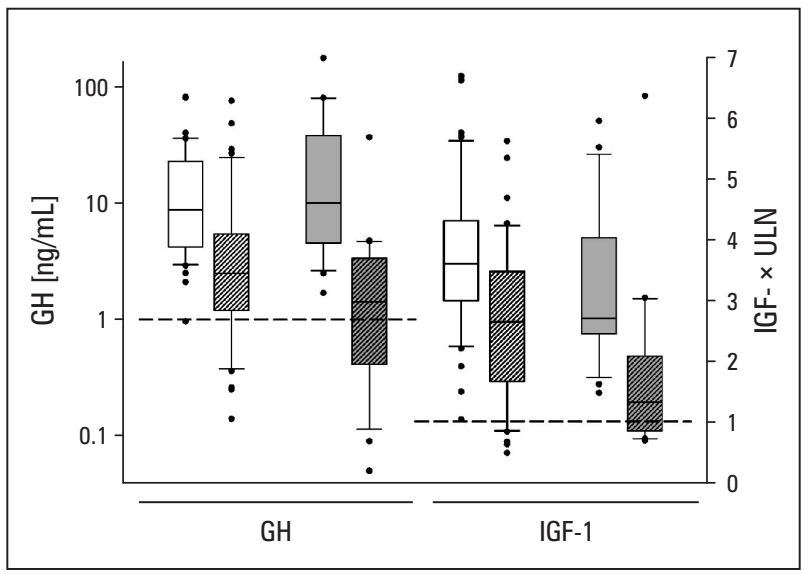

Figure 1. Preoperative (non-dashed) and postoperative (dashed) GH and IGF-1 in patients operated before 2016 (group 2 - white boxplots) or after 2016 (group 1 - grey boxplots). Dashed horizontal lines stand for normal values for both GH and IGF-1. Note that the GH axis is logarithmic. GH - growth hormone; IGF-1 - insulin-like growth factor 1

had normalised GH, 11 (26.2\%) had normalised IGF-1, and in eight both GH and IGF-1 were normal (19.0\%).

Both pre-surgery and post-surgery IGF-1 and GH values were available in 21 patients in the first group and in 41 patients in the second group.

Although median GH was similar between the two groups, median GH after surgery was lower in the first group ( $\mathrm{p}<0.05$ ) (see Fig. 1). Also, IGF-1 after surgery was lower in the first group, using covariance analysis $(\mathrm{p}<0.05)$ (see Fig. 1).

Pre and post medical treatment GH and IGF-1 values were available in 15 patients in the first group and 26 patients in the second group. Regarding medical treatment efficacy, we compared basal GH before medical treatment and after medical treatment between the two groups and observed that in the first group the mean GH before treatment was $5.64 \mathrm{ng} / \mathrm{mL}$ and in the second group it was $7.21 \mathrm{ng} / \mathrm{mL}$. After medical treatment the mean random $\mathrm{GH}$ was $2.51 \mathrm{ng} / \mathrm{mL}$ in the first group and $3.99 \mathrm{ng} / \mathrm{mL}$ in the second group. Mean IGF-1 before medical treatment in the first group was $2.4 \times \mathrm{ULN}$ and in the second group was $3.1 \times$ ULN. After receiving medical treatment the mean IGF- 1 was $1.6 \times$ ULN in the first group and $1.8 \times$ ULN in the second group. Covariance analysis resulted in there being no difference between the two groups.

\section{Discussion}

Our study presents the overall control rate of acromegaly in a sample of 186 patients assessed in a single tertiary centre in Romania between January $1^{\text {st }}, 2012$ and May $31^{\text {st }}, 2019$. Also, we present the evolution of 
the control rate of GH and IGF1 in patients diagnosed in the last three years.

Surgery was the preferred treatment of acromegaly. In our study $88.6 \%$ of patients underwent pituitary surgery, a proportion higher than in other countries (Mexico 70\% [7], Bulgaria 85.8\% [19], Spain 84\% [6], France $80 \%$ [9], Sweden $64 \%$ [11]). This may be explained by the fact that in Romania, medical treatment is reimbursed only in patients who have undergone pituitary surgery.

$65.2 \%$ of patients were on medical treatment at their last evaluation, a lower percentage than in Spain (74\%) [6] but higher than in some other countries (France $49.6 \%$ [9], Sweden $45 \%$ [11]).

Radiotherapy (41.9\% of patients) was used more extensively than in other countries (Germany 22\% [12], France 17\% [9], USA 20\% [9]). This difference may also be explained by the absence of widely spread SSA treatment until 2009 in Romania.

The surgical cure rate was $14.8 \%$ in our study, lower than in other studies made in different countries, which vary from 52 to $72 \%$ in centres presenting data on more than 100 patients [20]. Overall disease control (normal GH and IGF-1) was obtained with single or multimodal therapy in $46.7 \%$ of patients, also lower than in other countries (Finland 76\% ], Belgium 56\% [10], Canada $70 \%$ [8], UK 72\% [17], Germany 72\% [12]), but higher than in the previous study made in our centre $(28.6 \%)$ (16). This progress in disease control may be explained by the change in the Romanian protocol of treatment, which now fully reimburses second-generation SSA and the combination of SSA and pegvisomant.

In patients diagnosed in the last three years, who received at least one treatment, surgery was still the most used treatment - $26(72.2 \%)$ patients; medical therapy was used in $22(61.1 \%)$ patients, and only five $(13.8 \%)$ patients received radiotherapy.

We observed that remission after surgery was higher in patients diagnosed after March 2016. GH was normalised in $46.1 \%$ vs. $24.14 \%$, IGF-1 in $26.9 \%$ vs. $14.6 \%$, and both GH and IGF-1 in $26.9 \%$ vs. $9.7 \%$. This may be caused by a higher referral of patients to highly specialised centres in pituitary surgery. Also, disease control with medical treatment was higher in patients assessed in our clinic after March 2016. IGF-1 was normalised in $30.4 \%$ vs. $19.2 \%$, GH in $56.5 \%$ vs. $47.6 \%$, and both GH and IGF-1 in $30.4 \%$ vs. $15.4 \%$. The control rate in the first group of patients was also higher than in the second group (38.8\% vs. $19.2 \%)$. We also found that surgical outcome in terms of lowering IGF-1 was better in the first group ( $\mathrm{p}<0.05)$, and also random $\mathrm{GH}$ after surgery was lower in the first group ( $p<0.05)$.

Although the control rate with medical treatment was also higher in the first group, there is no difference in IGF-1 lowering with medical treatment between the two groups, so we can assume that the better disease control with medical treatment is also caused by better surgical outcome. Also, the lack of difference in IGF-1 lowering with medical treatment can also be caused by the shorter time of follow-up in the first group and the lack of full dose escalation in SSA.

\section{Conclusion}

Although disease control of acromegaly has improved in recent years in our tertiary centre, it remains lower than in other countries. Despite that, changes in Romanian protocol treatment seem to improve overall disease control in the long run, and highly specialised pituitary surgery centres improve the short-term outcome, with a higher cure rate and improvement in lowering IGF-1 and random GH. Longer follow-up studies need to be performed in order to have a proper dose escalation of SSA, with the addition of GH receptor blocker to the treatment.

\section{Funding}

No grants or founding sources.

\section{References}

1. Melmed S, Bronstein MD, Chanson P, et al. A Consensus Statement on acromegaly therapeutic outcomes. Nat Rev Endocrinol. 2018; 14(9): 552-561, doi: 10.1038/s41574-018-0058-5, indexed in Pubmed: 30050156.

2. Haliloglu O, Kuruoglu E, Ozkaya HM, et al. Multidisciplinary Approach for Acromegaly: A Single Tertiary Center's Experience. World Neurosurg. 2016; 88: 270-276, doi: 10.1016/j.wneu.2015.12.092, indexed in Pubmed: 26806060.

3. Cerit ET, Ağbaht K, Demir Ö, et al. Discordane between GH and IGF-1 levels in Turkish acromegalic patients. Endocr Pract. 2016; 22(12): 1422-1428, doi: 10.4158/EP161295.OR, indexed in Pubmed: 27631850.

4. Anagnostis P, Efstathiadou ZA, Polyzos SA, et al. Acromegaly: presentation, morbidity and treatment outcomes at a single centre. Int J Clin Pract. 2011; 65(8): 896-902, doi: 10.1111/j.1742-1241.2011.02682.x, indexed in Pubmed: 21679284.

5. Karapanou O, Tzanela M, Christoforaki M, et al. Therapeutic trends and outcome of acromegaly: a single center experience over a 40-year period. Hormones (Athens). 2016; 15(3): 368-376, doi: 10.14310/horm.2002.1680, indexed in Pubmed: 27394702.

6. Sesmilo G, Gaztambide S, Venegas E, et al. REA investigators. Changes in acromegaly treatment over four decades in Spain: analysis of the Spanish Acromegaly Registry (REA). Pituitary. 2013; 16(1): 115-121, doi: 10.1007/s11102-012-0384-x, indexed in Pubmed: 22481632.

7. Portocarrero-Ortiz LA, Vergara-Lopez A, Vidrio-Velazquez M, et al. Mexican Acromegaly Registry Group. The Mexican Acromegaly Registry: Clinical and Biochemical Characteristics at Diagnosis and Therapeutic Outcomes. J Clin Endocrinol Metab. 2016; 101(11): 3997-4004, doi: 10.1210/jc.2016-1937, indexed in Pubmed: 27428551.

8. Vallette S, Ezzat S, Chik C, et al. Emerging trends in the diagnosis and treatment of acromegaly in Canada. Clin Endocrinol (Oxf). 2013; 79(1): 79-85, doi: 10.1111/cen.12112, indexed in Pubmed: 23190441.

9. Maione L, Brue T, Beckers A, et al. French Acromegaly Registry Group. Changes in the management and comorbidities of acromegaly over three decades: the French Acromegaly Registry. Eur J Endocrinol. 2017; 176(5): 645-655, doi: 10.1530/EJE-16-1064, indexed in Pubmed: 28246150.

10. Bex M, Abs R, T'Sjoen G, et al. AcroBel--the Belgian registry on acromegaly: a survey of the 'real-life' outcome in 418 acromegalic subjects. Eur J Endocrinol. 2007; 157(4): 399-409, doi: 10.1530/EJE-07-0358, indexed in Pubmed: 17893253.

11. Esposito D, Ragnarsson O, Granfeldt D, et al. Decreasing mortality and changes in treatment patterns in patients with acromegaly from a nationwide study. Eur J Endocrinol. 2018; 178(5): 459-469, doi: 10.1530/EJE-18-0015, indexed in Pubmed: 29483205. 
12. Schöfl C, Franz H, Grussendorf M, et al. participants of the German Acromegaly Register. Long-term outcome in patients with acromegaly: analysis of 1344 patients from the German Acromegaly Register. Eur J Endocrinol. 2013; 168(1): 39-47, doi: 10.1530/EJE-12-0602, indexed in Pubmed: 23087126.

13. Bollerslev J, Heck A, Olarescu NC. Management of endocrine disease: Individualized Management of Acromegaly. Eur J Endocrinol. 2019; 181(2): R57-R71, doi: 10.1530/EJE-19-0124, indexed in Pubmed: 31100716

14. Valea A, Ghervan C, Carsote M, et al. Effects of combination therapy: somatostatin analogues and dopamine agonists on GH and IGF1 levels in acromegaly. Clujul Med. 2015; 88(3): 310-313, doi: 10.15386/cjmed-435, indexed in Pubmed: 26609262.

15. Kun I, Tanko Z, Nasalean A, et al. Multimodal management of $\mathrm{GH}$-secreting pituitary adenomas - the experience of the endocrinology department Tirgu-Mures, Romania, in the last decade. Endocrine Abstracts. 2015, doi: 10.1530/endoabs.37.ep794.

16. Niculescu DA, Baciu IF, Capatina C, et al. Acromegaly treatment in Romania. How close are we to disease control? Endokrynol Pol. 2017 68(5): 519-523, doi: 10.5603/EP.a2017.0041, indexed in Pubmed: 28879646.
17. Howlett TA, Willis D, Walker G, et al. UK Acromegaly Register Study Group (UKAR-3). Control of growth hormone and IGF1 in patients with acromegaly in the UK: responses to medical treatment with somatostatin analogues and dopamine agonists. Clin Endocrinol (Oxf). 2013; 79(5): 689-699, doi: 10.1111/cen.12207, indexed in Pubmed: 23574573.

18. Katznelson L, Laws ER, Melmed S, et al. Endocrine Society. Acromegaly: an endocrine society clinical practice guideline. J Clin Endocrino Metab. 2014; 99(11): 3933-3951, doi: 10.1210/jc.2014-2700, indexed in Pubmed: 25356808.

19. Vandeva S, Elenkova A, Natchev E, et al. Treatment outcome results from the Bulgarian Acromegaly Database: adjuvant dopamine agonist therapy is efficient in less than one fifth of non-irradiated patients. Exp Clin Endocrinol Diabetes. 2015; 123(1): 66-71, doi: 10.1055/s-0034-1389987, indexed in Pubmed: 25611123.

20. Buchfelder M, Schlaffer SM. The surgical treatment of acromegaly. Pituitary. 2017; 20(1): 76-83, doi: 10.1007/s11102-016-0765-7, indexed in Pubmed: 27770308.

21. Kauppinen-Makelin R, Sane T, Reunanen A, et al. A nationwide survey of mortality in acromegaly. J Clin Endocrinol Metab. 2005 ; 90(7): 4081-4086, doi: 10.1210/jc.2004-1381, indexed in Pubmed: 15886256. 